\title{
Analysis of logging parameter model of Jurassic complex reservoir in Xinjiang Shenquan Oilfield
}

\author{
Yanjie $\mathrm{Li}^{1,2}$, Yitong Wang ${ }^{1,2}$, Hansheng Ding ${ }^{1,2}$, Yongyi Ma ${ }^{1,2}$, Yan Shen ${ }^{1,2}$, Lilan Chu ${ }^{1,2}$, Zhiyang Nie ${ }^{1,2}$, Jinxia Du ${ }^{1,2}$, \\ Zhaoyi Shao ${ }^{1,2}$, Qicai Gao ${ }^{3}$ and Shuheng Wang ${ }^{1,2}$ \\ ${ }^{1}$ Exploration and Development Research Institute of Daqing Oilfield Co., Ltd., 163712 Daqing Heilongjiang, China \\ ${ }^{2}$ Key Laboratory of tight oil and shale oil accumulation of Heilongjiang province, 163712 Daqing Heilongjiang, China \\ ${ }^{3}$ Heilongjiang Province Key Research Laboratory in Tight Sandstone and Shale Oil Reservoir Accumulation,Daqing, China
}

\begin{abstract}
The study discusses the characteristics of Jurassic reservoir in Shenquan Oilfield in Xinjiang. The reservoir of Qiketai Sanjianfang formation mainly develops delta front facies and shore shallow lake facies sand bodies. The lithological characteristics of the reservoir are mainly fine sandstone and siltstone, and the physical properties of the target layer are mainly medium porosity and medium permeability. The Jurassic reservoir space in Shenquan Oilfield is sandstone pore type, mainly composed of secondary pores, mainly including intergranular dissolved pores, intragranular dissolved pores and intercrystalline pores, with good connectivity between pores. According to the analysis data of well logging, core analysis, production performance and DST in Shenquan Oilfield, porosity, permeability and water saturation models are established respectively:The porosity interpretation model is established by using acoustic wave and shale content; the permeability parameter interpretation model is realized by applying graph based cluster analysis method and neural network algorithm. The oil saturation interpretation model is obtained by Archie formula. According to the logging interpretation model and interpretation results, it can meet the needs of reservoir evaluation, oil-water distribution and original geological reserve parameters. After analyzing the logging parameter model and reservoir parameter calculation method, it is considered that the Jurassic in the Shenquan Oilfield in Xinjiang has better physical properties.
\end{abstract}

\section{Introduction}

The aimed area is located in the east of Xinjiang Uygur Autonomous Region, about $8 \mathrm{~km}$ northeast of Turpan city with about $20 \mathrm{~km}$ long from east to west and $11 \mathrm{~km}$ wide from north to south. There are Shenquan oil production plant and some villages in the seismic work area, and the southeast corner is close to Astana ancient tomb group (Fig. 1). The seismic area of Shenquan Oilfield covers $95 \mathrm{~km} 2$, with a total of 304 wells and more than 40 faults. As a whole, Shenquan Oilfield is dominated by complex fault-block reservoirs controlled by anticline structures, followed by lithologic reservoirs. Due to fault cutting, many fault nose and fault block traps are developed. Oil bearing intervals are principally developed in Tertiary Shanshan Group, Cretaceous Tugulu group and Jurassic Qiketai formation and Sanjianfang formation (Table 1).

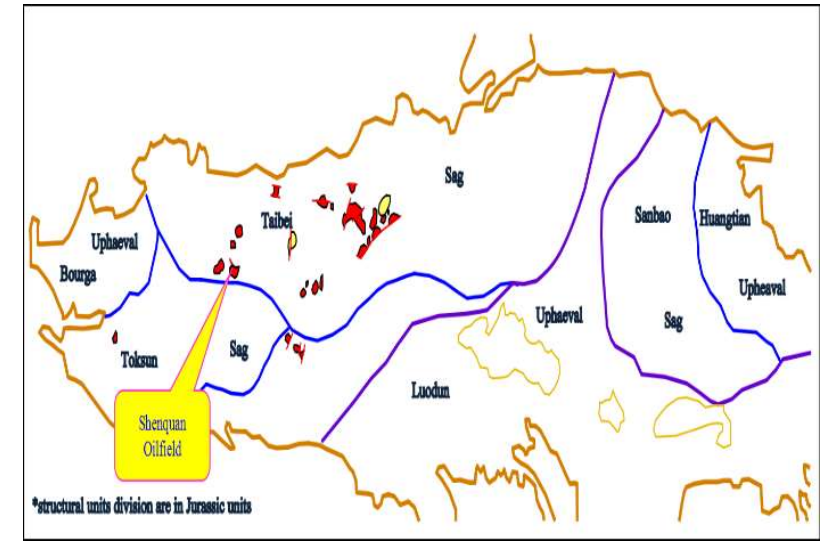

Fig. 1 Three dimensional geographical location of Shenquan in Turpan Hami Basin

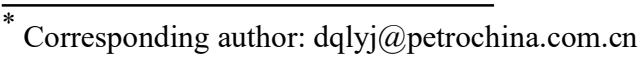


Table 1 Comparison of standard formation profiles in Shenquan Oilfield

\begin{tabular}{|c|c|c|c|c|c|c|}
\hline \multicolumn{3}{|c|}{ Stratigraphy } & \multicolumn{3}{|c|}{$\begin{array}{l}\text { Lithology section } \\
\end{array}$} & \multirow[b]{2}{*}{$\begin{array}{r}\text { Pressure } \\
\text { coefficien }\end{array}$} \\
\hline System & Series & Formation & $\begin{array}{c}\text { Thickness } \\
(\mathrm{m})\end{array}$ & $\begin{array}{c}\text { Lithology } \\
\text { description }\end{array}$ & $\begin{array}{c}\begin{array}{c}\text { Oil and } \\
\text { gas } \\
\text { interval }\end{array}\end{array}$ & \\
\hline Quaternary & $\begin{array}{l}\text { Holocene- } \\
\text { Pleistocene }\end{array}$ & Q & 85 & $\begin{array}{c}\text { Variegated } \\
\text { conglomerate }\end{array}$ & $\begin{array}{c}\begin{array}{c}\text { Oil and } \\
\text { gas } \\
\text { interval }\end{array} \\
\end{array}$ & 1.0 \\
\hline \multirow[b]{3}{*}{ Tertiary } & Pliocene & $\mathrm{N} 2 \mathrm{p}$ & 913 & $\begin{array}{c}\text { Interbedding } \\
\text { of variegated } \\
\text { conglomerate } \\
\text { and brownish } \\
\text { yellow } \\
\text { mudstone }\end{array}$ & & 1.0 \\
\hline & $\begin{array}{l}\text { Oligocene- } \\
\text { Miocene }\end{array}$ & N1t & 488 & $\begin{array}{c}\text { Brownish } \\
\text { yellow and } \\
\text { brownish red } \\
\text { mudstone with } \\
\text { white gypsum } \\
\text { layer }\end{array}$ & & 1.0 \\
\hline & $\begin{array}{l}\text { Paleocene } \\
\text { Esh }\end{array}$ & Esh & 424 & $\begin{array}{c}\text { Dark purple } \\
\text { mudstone is } \\
\text { mainly } \\
\text { intercalated } \\
\text { with gypsum } \\
\text { mudstone and } \\
\text { silty } \\
\text { mudstone, } \\
\text { with a layer of } \\
\text { gray sandy } \\
\text { conglomerate } \\
\text { and fine } \\
\text { sandstone } \\
\text { developed at } \\
\text { the bottom }\end{array}$ & $\begin{array}{c}\text { Oil and } \\
\text { gas } \\
\text { interval }\end{array}$ & 1.0 \\
\hline Cretaceous & Lower & K1tg & 155 & $\begin{array}{l}\text { A large set of } \\
\text { dark purple } \\
\text { and purplish } \\
\text { red mudstone } \\
\text { is mainly } \\
\text { mixed with } \\
\text { siltstone and } \\
\text { argillaceous } \\
\text { siltstone } \\
\text { locally }\end{array}$ & $\begin{array}{c}\text { Oil and } \\
\text { gas } \\
\text { interval }\end{array}$ & 1.0 \\
\hline \multirow[b]{3}{*}{ Jurassic } & Upper & $\mathrm{J} 3 \mathrm{q}$ & 248 & $\begin{array}{c}\text { Mainly } \\
\text { brownish red } \\
\text { and purplish } \\
\text { red mudstone }\end{array}$ & & 1.0 \\
\hline & \multirow[b]{2}{*}{ Middle } & $\mathrm{J} 2 \mathrm{q}$ & 55 & $\begin{array}{c}\text { The upper } \\
\text { section is gray } \\
\text { mudstone with } \\
\text { thin layer of } \\
\text { gray siltstone, } \\
\text { and the lower } \\
\text { section is gray } \\
\text { argillaceous } \\
\text { siltstone, } \\
\text { sandstone and } \\
\text { gray mudstone } \\
\text { interbedding }\end{array}$ & & 1.0 \\
\hline & & $\mathrm{J} 2 \mathrm{~s}$ & 300 & $\begin{array}{c}\text { Dark gray } \\
\text { mudstone is } \\
\text { interbedded } \\
\text { with light gray } \\
\text { siltstone, fine } \\
\text { sandstone, } \\
\text { coarse } \\
\text { sandstone, } \\
\text { gravelly } \\
\text { sandstone and } \\
\text { glutenite in } \\
\text { unequal } \\
\text { thickness, } \\
\text { intercalated } \\
\text { with a thin } \\
\text { layer of } \\
\text { variegated and } \\
\text { grayish yellow } \\
\text { mudstone }\end{array}$ & $\begin{array}{c}\text { Oil and } \\
\text { gas } \\
\text { interval }\end{array}$ & 1.1 \\
\hline
\end{tabular}

\section{Reservoir characteristics}

The Jurassic Qiketai Sanjianfang formation in Shenquan Oilfield mainly develops delta front facies and shore shallow lake facies sand bodies. The lithological characteristics of the reservoir are dominated by fine sandstone and siltstone, accounting for $37.5 \%$ and $25 \%$, respectively, followed by unequal-grained sandstone, accounting for $25 \%$ which mostly feldspar lithic sandstone. Sandstone types include gravel-bearing gravel sandstone, medium sandstone, fine sandstone, and siltstone, with various types and low structural maturity. The clastic components are mainly rock debris, feldspar and quartz. The content of feldspar is $10-35 \%$, with an average of $22 \%$. Quartz content accounts for $28.8 \%$, feldspar $21.11 \%$ and rock debris $49.18 \%$. Core analysis data describes that the physical properties of the target layer are chiefly medium porosity and medium permeability, followed by medium porosity and low permeability. The highest average porosity of layer S1 is $19.6 \%$, and the highest average permeability is $265.4 \mathrm{mD}$. The lowest average porosity of layer 2 is $16.6 \%$, besides the lowest average permeability of layer Q is $65.3 \mathrm{mD}$. The porosity distribution range is basically of $20 \sim 24 \%$; the permeability distribution range is mainly between $100 \mathrm{mD}$ and $500 \mathrm{mD}$ (Table 2). Depending on the observation and identification of rock flakes, cast flakes, and scanning electron microscopy, the Jurassic reservoir space in Shenquan Oilfield is sandstone pore type, mainly composed of secondary pores, including intergranular dissolved pores, intragranular dissolved pores and intercrystalline pores with diameter of $20 \mu \mathrm{m} \sim 90 \mu \mathrm{m}$, and pores is well connected. Additionally, there are a small amount of residual primary intergranular pores.

Table 2 Analysis of core physical properties in Shenquan Oilfield

\begin{tabular}{|c|c|c|c|c|c|c|}
\hline \multirow{2}{*}{$\begin{array}{c}\text { Oil } \\
\text { deposit }\end{array}$} & \multicolumn{3}{|c|}{$\begin{array}{c}\text { Porosity } \\
(\%)\end{array}$} & \multicolumn{3}{c|}{$\begin{array}{c}\text { Permeability } \\
\left(10^{-3} \mu \mathrm{m}^{2}\right)\end{array}$} \\
\cline { 2 - 7 } & Max & Min & Ave & Max & Min & Ave \\
\hline Q & 8 & 26.6 & 16.9 & 0.05 & 323 & 65.3 \\
\hline S1 & 4.8 & 26.9 & 19.6 & 0.2 & 2127 & 265.4 \\
\hline S2 & 13 & 20.7 & 16.6 & 2.21 & 569 & 131 \\
\hline J2s & 4.6 & 26.5 & 18 & 0.2 & 2127 & 200 \\
\hline
\end{tabular}

\section{Logging parameter interpretation model}

\subsection{Porosity parameter model}

Porosity reflects the ability of fluid storage in the reservoir. Due to the different types of minerals in the target formation in different study areas, the response coefficients of various types of minerals to a certain physical measurement method are also different. If the response equations are established for various types of minerals in the formation rocks, the results will be absolutely uncertain and difficult to operate. Therefore, for sandstone reservoir, it is generally assumed that in the formation rock with volume of "1", its constituent minerals are simplified as argillaceous minerals, skeleton minerals and pores, and the pores contain oil, gas and water fillers, which is commonly referred to as "volumetric physical model".

In the process of establishing the log interpretation porosity model, normally we apply core porosity analysis data to construct a relationship with various logging data reflecting porosity, such as density, sonic and neutron logging curves. Occasionally use multiple regression method, and finally the most reasonable functional relationship is selected as the porosity calculation model. 
This is commonly known as "core calibration logging" technology.

$$
\begin{gathered}
\Phi=0.1235 \mathrm{AC}-16.77 \quad(\mathrm{AC} \leq 305 \mu \mathrm{s} / \mathrm{m}) \\
(\mathrm{N}=12, \quad \mathrm{R}=0.976) \\
\Phi=0.1097 \mathrm{AC}-16.29 \quad(\mathrm{AC} \geq 305 \mu \mathrm{s} / \mathrm{m}) \\
(\mathrm{N}=7, \quad \mathrm{R}=0.894)
\end{gathered}
$$

This formula is established based on the coring analysis data at different stages. The porosity is divided to two cases with the sonic logging value of $305 \mu \mathrm{s} / \mathrm{m}$ as the boundary. The main issue of calculating the porosity is that when the acoustic logging value is at $305 \mu / \mathrm{m}$, the calculated porosity will have a discontinuous abrupt value. The reason for this situation is that the establishment of formula (2) is mainly based on the core analysis data of well S1, and the acoustic time difference logging value of the standard formation of well S1 is obviously higher than that of other exploratory wells. Therefore, the sonic logging value of well S1 must be standardized. On the basis of standardized treatment, parameter optimization and correlation comparison show that there is a good correlation between acoustic wave, shale content and porosity (Fig. 2 and Fig. 3).

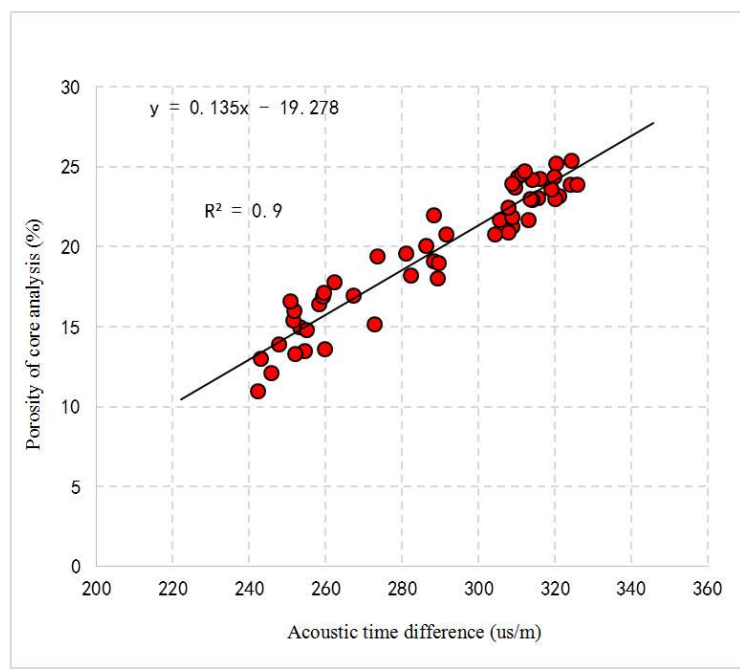

Fig. 2 The relationship between porosity and acoustic time difference

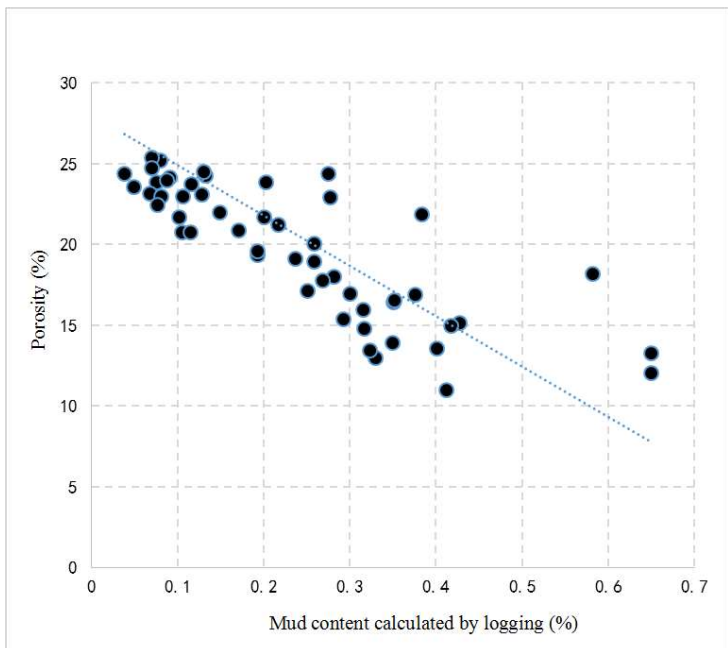

Fig. 3 Relationship between porosity and shale content
In this study, the porosity calculation formula is established by acoustic wave and shale content and 52 sub-layers of 6 wells: $\Phi=0.117 *$ ac-5.616*vsh-12.686, correlation coefficient 0.925 , average relative error $5.1 \%$ (Fig. 4).

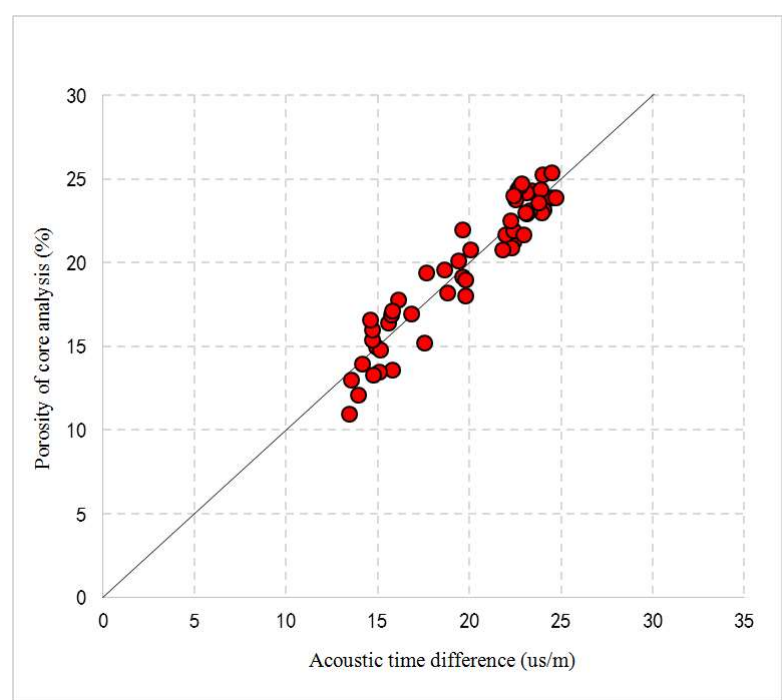

Fig. 4 Comparison of porosity accuracy between logging calculation and core analysis

Figure 5 exhibits an example of porosity calculation. The coring depth of well Shen105 is $2512-2516 \mathrm{~m}$, and the acoustic moveout value of the coring section is above $305 \mu \mathrm{s} / \mathrm{m}$, according to the original calculation method, formula (2) will be practised for calculation. It is obvious that the porosity calculated by logging is too small (the second curve trace on the right in the figure), and the relative error reaches more than $15 \%$, while the calculation by the new regression formula is in good agreement with the core analysis (the first curve trace on the right), and the relative error is less than $5 \%$. The reliability of the porosity method is further verified.

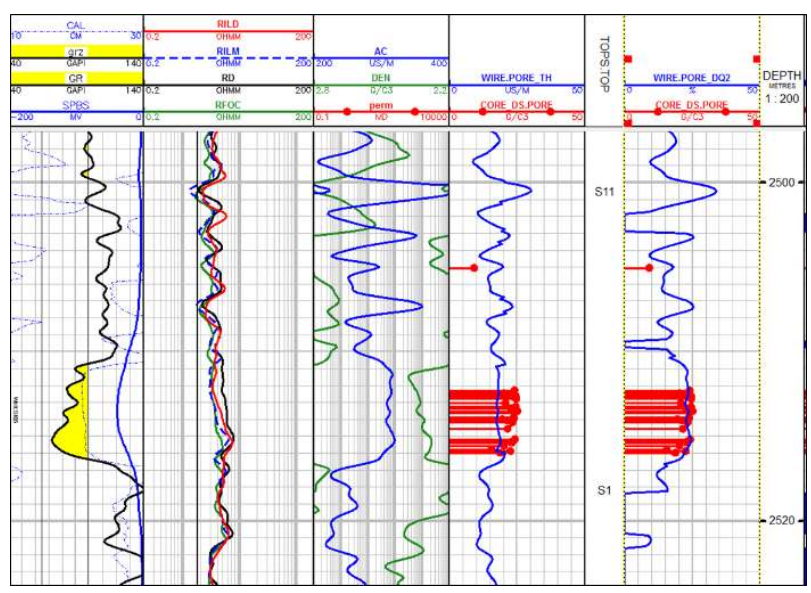

Fig. 5 Porosity calculation effect of coring section of well Shen 105

\subsection{Permeability parameter model}

Reservoir permeability and porosity are important parameters of logging interpretation. Scholars at home 
and abroad have done a lot of research work on them, and put forward many mature theoretical and empirical calculation formulas based on rock volume physical model. These two parameters reflect the characteristics of reservoir from different aspects. They are both related and different. They are closely related to the pore volume of reservoir, and are also controlled by the geometric size, shape and distribution of pores. In reservoir physics, the well-known Kozeny equation is used to describe and calculate permeability which is only applicable to relatively pure and well consolidated formations with medium and high porosity $(>15 \%)$, but not to low porosity and low permeability formations.

Adopting graph based cluster analysis method, this method analyzes and classifies logging curve data considering curve shape, distribution density, and correlation, automatically determines the number of optional clusters, and realizes permeability parameter interpretation via neural network algorithm. Preferably, $\mathrm{AC}, \mathrm{VSH}, \mathrm{DEN}, \mathrm{CNL}$ and other curves are interpreted by self-organizing mapping algorithm to achieve permeability parameter interpretation, and the calculation accuracy coincidence rate is $91.2 \%$ (Fig. 6).

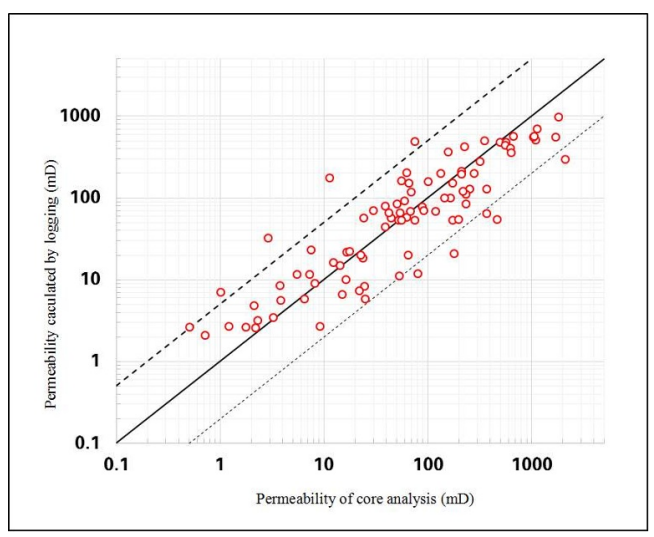

Fig. 6 Comparison of permeability accuracy between logging calculation and core analysis

Take the coring section of well Shen104 as an example (Fig. 7). The permeability calculated by the new method (the second curve channel in the right) obviously better agrees with the core analysis data and the trend is significantly better than the permeability calculated by the original method(the first curve channel in the right).

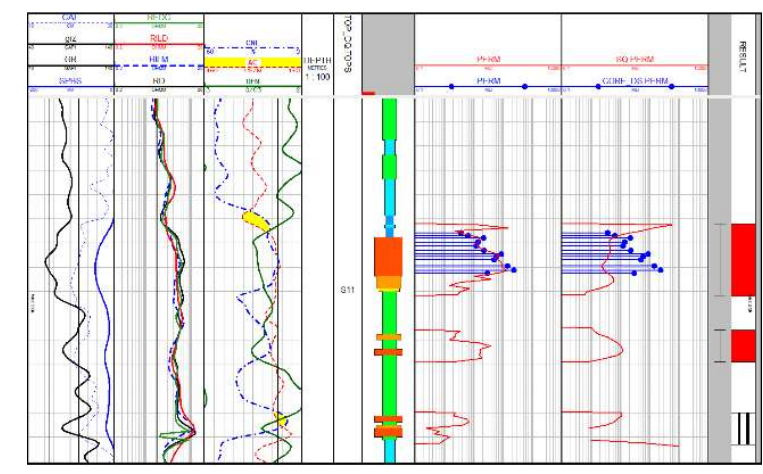

Fig. 7. Comparison of permeability effect of well Shen 104 logging calculation

\subsection{Water saturation model}

As an important index to evaluate the oil bearing property of reservoir, saturation is one of the essential parameters in logging quantitative interpretation. Over the years, logging academic circles at home and abroad have carried out in-depth research around the oil saturation model of argillaceous sandstone reservoir. Each model indicates different argillaceous sandstone reservoir characteristics from a certain aspect, or develops different understanding of argillaceous conductivity to some extent.

For a long time, the interpretation model based on resistivity has been dominant. For example, the W-S model and two water model based on the cation exchange properties of clay minerals. Ran et al. (1990) proposed the extended Archie formula (EAE), Iivar et al. (1991) suggested the particle conductivity method of argillaceous sandstone, Charles $(1995,1996)$ constructed the effective medium model (EMM), and Givens (1987, 1989) proposed the rock skeleton conductivity model (crmm), $\mathrm{Xu}$ Dong Jing et al. generalized empirical relationship model (GEM) between resistivity increase coefficient and saturation. These conductivity models have certain application value for evaluating oil and gas reservoirs using logging data in China. In the process of selecting the saturation model, the rock composition, mineral structure and related influencing factors of the reservoir in the study area is necessary to be analyzed. According to the application conditions of different models, Archie formula, Indonesian equation, W-S model and double water model should be extensively applied to calculate the reservoir saturation parameters. Although some other logging techniques such as carbon-oxygen ratio and nuclear magnetic resonance can also provide relevant information on reservoir saturation, in the current logging interpretation, the most used and most widely studied is still based on resistivity saturation model.

The distribution form of shale in the study area is closer to dispersed shale, and the formation water salinity is between 160,000 and $250,000 \mathrm{mg} / \mathrm{L}$, which is a highsalinity reservoir with low shale content.Therefore, Archie formula is selected. The formula is as follows:

$$
\begin{aligned}
S_{w} & =\left(\frac{a b R_{w}}{\Phi^{m} R_{t}}\right)^{1 / n} \\
\mathrm{~S}_{o} & =1-\mathrm{S}_{w}
\end{aligned}
$$

$\mathrm{S}_{o}, \mathrm{~S}_{w}$ - oil saturation, water saturation, $\mathrm{f} ; \mathrm{m}, \mathrm{n}$ - rock cementation index and saturation index;

$\mathrm{R}_{w}$ - formation water resistivity, $\Omega \mathrm{m} ; \mathrm{R}_{t}$ - reservoir resistivity, $\Omega \mathrm{m} ; \quad \Phi$ - Reservoir porosity,f.

The critical parameters of Archie saturation model is the determination of $a, b 、 m 、 n$, as well as the formation water resistivity $R_{w}$ and the formation resistivity $R_{t}$, in the meantime the accuracy that directly determines the oil saturation precision. Water saturation is obtained by Archie formula, and according to the reservoir characteristics and the petroelectric test results of well Shen2, well Shengnan 2 and well Shengnan 203 (Fig. 8 and Fig. 9). The model parameters are decided as follows: $\mathrm{a}=1.0, \mathrm{~B}=1.3, \mathrm{~m}=1.83, \mathrm{n}=1.71$ 


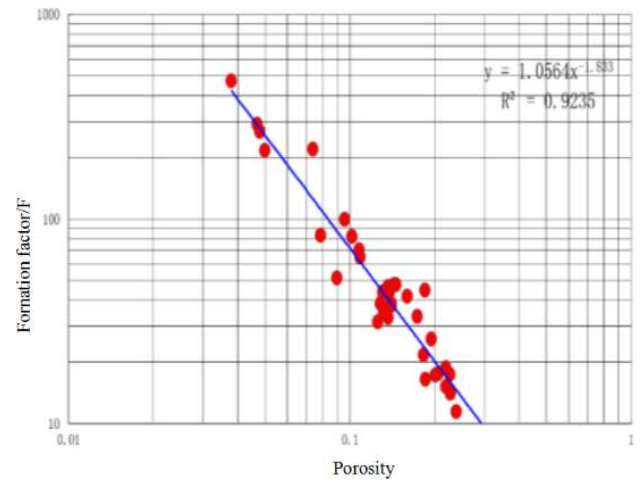

Fig. 8 Relationship between resistivity increase rate and saturation

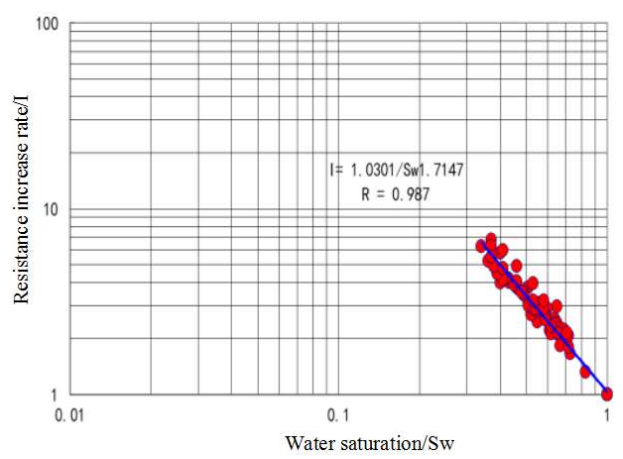

Fig. 9 Relationship between resistivity increase rate and saturation

Due to the large amount of perforation production data and water analysis data in the study area, in the process of saturation calculation, the well logging intersection Pickt map is established by the well logging data of the production well (well Shen103) at the edge of the structure, and the petroelectric parameters of the saturation model are modified through the "water line" of the intersection map (Fig. 10).

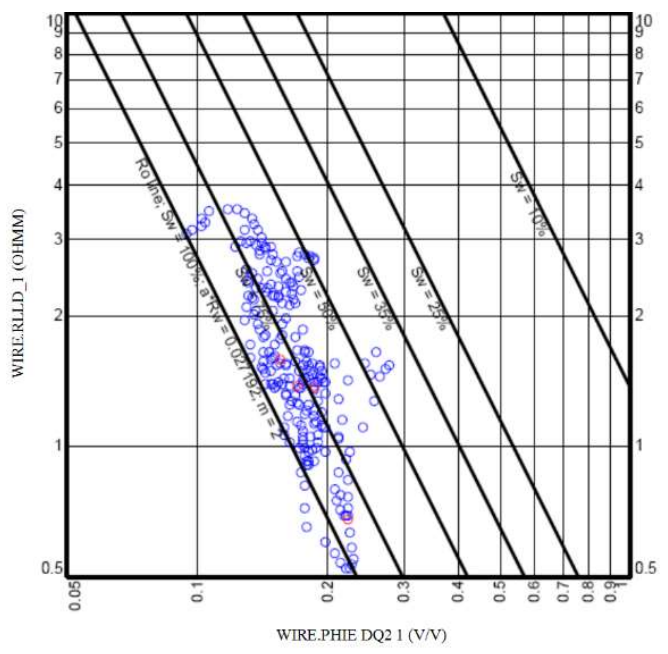

Fig. 10 Cross plot of porosity and resistivity

As the oil-water relationship of Shenquan Oilfield is complex, fault blocks are developed, reservoirs are developed with multiple and thin layers, and the original oil-water interface has been destroyed under the influence of later structure, it is difficult to accurately determine the original oil column height, which affects the calculation of original oil saturation.

\section{Conclusion}

(1) Delta front facies and shore shallow lake facies sand bodies are primarily developed in Jurassic Qiketai Sanjianfang formation of Shenquan Oilfield in Xinjiang. The lithological characteristics of the reservoir are mainly fine sandstone and siltstone, and the physical properties of the target layer are mostly medium porosity and medium permeability.

(2) After analyzing the logging parameter model and the calculation method of reservoir parameters, it is concluded that the Jurassic of Xinjiang Shenquan Oilfield has better physical properties. The average porosity is $18.0 \%$, and the average permeability is $230.6 \mathrm{mD}$, belonging to medium porosity and medium permeability reservoir.

(3) The appropriate porosity, permeability, and water saturation models of the study area were established through logging, and parameters such as porosity, permeability, and water saturation were calculated, which supplies a good fundamental value for reservoir identification accuracy and reserve parameter logging evaluation method, meanwhile effectively supports the exploration and evaluation project.

\section{References}

1. Zeng W.C., Well logging evaluation technology of oil and gas reservoirs. Well logging evaluation technology of oil and gas reservoirs, (1947).

2. He X.P., Reservoir logging evaluation technology of oil and gas reservoirs. Petroleum geology and engineering, 20, 5 (2006).

3. Zhai Y.M., Cai B.J., Zhang Q.M., Analysis of oil and gas accumulation conditions in the south slope of Turpan Depression . Xinjie oil and gas, 9, 1 (2013)

4. Ren J.W., La Q.L., Study on logging parameters of oil reserves in an area. Petrochemical technology, 2, (2017)

5. Luo S.Q., Wu Y.F., Chen X., Application of model inversion technology in shallow reservoir research. Xinjiang Petroleum Geology, 21, 4 (2000).

6. Qiao T.T., Qi X.L., He T.H.,Research on logging interpretation technology of low porosity and permeability reservoir in Shan 23 member of Su 77 block . Foreign logging technology, 6 (2013) .

7. Yin H.R., Zhou H., He W.J., Interpretation model of reservoir logging parameters and lower limit standard of reservoir evaluation in Zhuang 9 Chang 8_ (2) in Heshui Oilfield .Journal of Changjiang University: Natural Science Edition, 8, 2 (2021).

8. Liu Z.D., Shi Y.J., Zhou J.Y., ummary and applicability analysis of methods for determining the lower limit of effective reservoir physical properties. progress in Geoscience, 33, 3 (2018). 